\title{
Changes of Phospholipids in Duck Muscle by Different Heating Methods
} D Y Wang, F Liu, Y Z Zhu and W M Xu*

Institute of Agricultural Products Processing, Jiangsu Academy of Agricultural Sciences, Nanjing 210014, P. R. China

\begin{abstract}
We studied the changes in intramuscular phospholipids on boiling and roasting duck meat. Intramuscular lipids were distilled using chloroform and methanol. The phospholipids were separated using solid phase extraction (SPE) and analyzed with high performance liquid chromatography(HPLC). The fatty acid composition of phosphatidylethanolamine (PE) and phosphatidylcholine (PC) was determined using gas chromatography-mass spectroscopy(GC-MS), and the molecular species were analyzed using HPLC-MS. The results showed that the phospholipid content decreased on cooking, and the decrease was greater with roasting. The decrement in PE was greater than that in PC, primarily because the former contains more polyunsaturated fatty acids. The relative polyunsaturated fatty acid content and the PE and PC molecular species with polyunsaturated fatty acids all decreased.
\end{abstract}

Keywords: Duck; Cooking; Phospholipids; Changes

\section{Introduction}

Phospholipids comprise the main constituent of membranes, and are thus one of the chemical foundations of life [1]. They are also important in nutrition and as flavor precursors. Phospholipids are formed from one molecule of glycerol, one molecule of a phosphorylated alcohol, and two molecules of a characteristic fatty acid [1]. They have a high hydrolyzable capability due to their molecular structure and are prone to oxidation due to the high unsaturated fatty acid content in the fatty acid component [2].

Phospholipids and triacylglycerol are the major substrate of lipid oxidation. The degree of phospholipid hydrolyzation varies with animal species and muscle type and affects the storability of meat and cooking methods [2]. The high oxidation activity of phospholipids is due to the component long-chain polyunsaturated fatty acids, which are easily oxidized. In addition, as membrane components, phospholipids are in close contact with lipid oxidation catalysts in the cytoplasm [3]. Phosphatidylethanolamine is especially susceptible to oxygen because of its high content of long-chain polyunsaturated fatty acids $[1,4]$ studied the change in the carcass phospholipids of chicken while cooking. They showed that cooking damaged phosphatidylethanolamine more seriously than phosphatidylcholine. Cooking oxidized some of the polyunsaturated fatty acids in phospholipids. Since the increase in the degree of oxidation was accompanied by an increase in the number of double bonds in the fatty acid carbon chains, a small amount $(0 \sim 45 \%)$ of linoleic acid was lost, while $50 \sim 70 \%$ of the arachidonic acid was lost and the loss of docosapentaenoic and docosahexaenoic acids was $70 \sim 100 \%$. No domestic or foreign reports about the change of phospholipids in duck on cooking were found. We analyzed the changes in intramuscular phospholipids in duck muscle with different cooking methods, especially the main phospholipids phosphatidyl choline (PC) and phosphatidylethanolamine (PE).

\section{Materials and Methods}

\section{Instrumentation}

The analyses were performed using a Waters 600 HPLC system(equipped with a Waters DC 2487 UV detector), Agilent 1100 high-performance liquid chromatography(HPLC) system(equipped with an autoinjector, HPLC workstation, UV detector, etc.), Alltech 2000 evaporative light scattering detector(ELSD), Waters Platform ZMD 4000 HPLC-mass spectroscopy(MS) system, TRACE gas chromatography(GC)-MS, Ultra Turrax T 25 homogenizer(IKR),
Allegra 64R refrigerated centrifuge(Beckman), RE-85C vacuum rotary evaporator(Shanghai Yarong), and $100 \mathrm{mg}$ Bond Elut LRC-NH2 cartridges (Varian).

\section{Materials}

Eighteen samples of biceps femoris were obtained from salted ducks. The raw duck meat was either boiled in water for $30 \mathrm{~min}$ or roasted by hanging in a tunnel oven at $90^{\circ} \mathrm{C}$ for $1.0 \mathrm{~h}$. Standard samples of phosphatidylcholines(PCs, from vitellus), phosphatidyleth anolamines(PEs, from bovine brain), phosphatidylinositols(PIs, from vitellus), phosphatidylserines(PSs, from vitellus), sphingomyelin( $\mathrm{SPH}$, from bovine brain), lysophosphatidylcholine(LPC, from bovine brain), phosphatidic acid(PA, from vitellus), C14:0, C14:1, C16:0, C18:0, C18:1, C18:2, C20:4, C22:4, C22: 6, and C24:2 fatty acids were purchased from Sigma Chemical.The chloroform, acetic acid, diethyl ether, 2,2-dimethoxypropane, $\mathrm{BF}_{3} \mathrm{NaCl}$, and $\mathrm{CaCl} 2$ were of analytical grade and the methanol, n-hexane, 2-propanol, and acetonitrile were of chromatographic grade.

\section{Lipid extraction}

Duck biceps femoris muscles were trimmed carefully to remove any adipose tissues and minced in a blender. The lipids were extracted from $3.0 \mathrm{~g}$ of muscle according to the method of Folch et al. [5]. The method consists of homogenizing the tissue with a chloroform/ methanol $(2: 1, \mathrm{~V}: \mathrm{V})$ mixture and washing the extract by adding 0.2 times its volume of an appropriate salt solution $\left(7.3 \mathrm{~g} \cdot \mathrm{L}^{-1} \mathrm{NaCl}, 0.5\right.$ $\left.\mathrm{g} \cdot \mathrm{L}^{-1} \mathrm{CaCl}_{2}\right)$. The resulting mixture was centrifuged for $15 \mathrm{~min}$ at $4^{\circ} \mathrm{C}$ at 3,000 rpm to separate it into two phases. The lower phase was the total pure lipid extract. The lipid extract was dried under a vacuum in a rotary evaporator at $40^{\circ} \mathrm{C}$. The $20.0 \mathrm{mg}$ residue was dissolved in $1.0 \mathrm{~mL}$ of chloroform for lipid fractionation.

*Corresponding author: W M Xu, Institute of Agricultural Products Processing Jiangsu Academy of Agricultural Sciences, China, Tel: 86-25-84390065; Fax: 8625-84390065; E-mail: weiminxu2002@yahoo.com.cn

Received August 08, 2011; Accepted September 27, 2011; Published September 29, 2011

Citation: Wang DY, Liu F, Zhu YZ, Xu WM (2011) Changes of Phospholipids in Duck Muscle by Different Heating Methods. J Food Process Technol 2:121. doi:10.4172/2157-7110.1000121

Copyright: (C) 2011 Wang DY, et al. This is an open-access article distributed under the terms of the Creative Commons Attribution License, which permits unrestricted use, distribution, and reproduction in any medium, provided the original author and source are credited. 


\section{Lipid fractionation}

Fractionation was used to obtain the phospholipids. The lipid classes were separated using the method of [6]. Briefly, $0.5 \mathrm{~mL}$ of dissolved extract(10.0 mg lipids) was percolated through an aminopropyl silica mini-column(100 mg, Varian) and washed in turn with $2.0 \mathrm{~mL}$ chloroform/2-propanol(2:1, V:V) and with $3.0 \mathrm{~mL}$ of $2 \%$ acetic acid in diethyl ether(W:W). Finally, the phospholipids were eluted with 3.0 $\mathrm{mL}$ of methanol. The solution was evaporated under $\mathrm{N}_{2}$ using a water bath at $40^{\circ} \mathrm{C}$, and the residue was redissolved in $0.3 \mathrm{~mL}$-hexane $/ 2$ propanol/water(120:80:11, V:V:V). The samples were kept at $-20^{\circ} \mathrm{C}$

\section{HPLC analysis of phospholipids}

The sample was analyzed in an Agilent 1100 HPLC system using a Lichrosorb SI $60-5$ silica gel column $(5 \mu \mathrm{m}, 250 \mathrm{~mm} \times 4.0 \mathrm{~mm}$ i.d) operating at $30^{\circ} \mathrm{C}$. A gradient elution was carried out at a flow rate of $1.0 \mathrm{~mL} \cdot \mathrm{min}^{-1}$ using different ratios of solutions $\mathrm{A}$ (n-hexane/2-propanol, 3:2, V: V), B(n-hexane/2-propanol/25 mmol. $\mathrm{L}^{-1} \mathrm{NH}_{4 \mathrm{Ac}}$ 120:80:11, V: $\mathrm{V}: \mathrm{V})$, and C(n-hexane/2-propanol/H2O, 120:80:11, V: V: V). The best separation was obtained using the following gradient: from 0 to $5 \mathrm{~min}$, $\mathrm{B}$ was increased from 0 to $50 \%$; from 5 to $30 \mathrm{~min}, \mathrm{~B}$ was increased from 50 to $100 \%$; from 30 to $45 \mathrm{~min}$, B was kept constant at 100\%; from 45 to $50 \mathrm{~min}, \mathrm{C}$ was increased from 0 to $100 \%$; from 50 to $60 \mathrm{~min}, \mathrm{C}$ was kept constant at $100 \%$; from 60 to $62 \mathrm{~min}$, A was increased from 0 to $100 \%$; from 62 to $70 \mathrm{~min}$, solution A was kept constant at $100 \%$. Chromatographic peaks were detected with a UV detector and ELSD, which were installed in series; the UV absorbance was measured at 205 $\mathrm{nm}$ and the ELSD was run at $70^{\circ} \mathrm{C}$ with $\mathrm{N} 2$ at $1.8 \mathrm{~L} \cdot \mathrm{min}^{-1}$.

\section{Preparation of the PCs and PEs}

The samples were prepared using the Waters 600 HPLC system using a $\mu$-Porasil semi-preparative silica gel column $(10$ $\mu \mathrm{m}, 300 \mathrm{~mm} \times 10 \mathrm{~mm}$ i.d) operating at $30^{\circ} \mathrm{C}$, with an injection volume of $200 \mu \mathrm{L}$. Chromatographic peaks were identified using the UV absorbance at $205 \mathrm{~nm}$. A gradient elution was carried out at a flow rate of $3.0 \mathrm{~mL} \cdot \mathrm{min}^{-1}$ using different ratios of solutions A (n-hexane/2propanol, 3:2, V:V) and $\mathrm{B}\left(\mathrm{n}\right.$-hexane/2-propanol/25 mmol.L-1 $\mathrm{NH}_{4 \mathrm{Ac}}$ $120: 80: 11, V: V: V)$. The best separation was obtained using the following gradient: from 0 to $5 \mathrm{~min}$, B was increased from 0 to $50 \%$; from 5 to $30 \mathrm{~min}$, B was increased from 50 to $100 \%$; from 30 to $60 \mathrm{~min}$, B was kept constant at $100 \%$; from 60 to $62 \mathrm{~min}$, B was reduced from 100 to $0 \%$; from 62 to $70 \mathrm{~min}$, solution A was kept constant at $100 \%$. The PCs and PEs were identified by comparing their retention times with standard samples [7]. PCs and PEs were collected five times from the column outlet; the collected solution was dried under vacuum in a rotary evaporator at $40^{\circ} \mathrm{C}$. Two aliquots of $0.5 \mathrm{~mL} \mathrm{n}$-hexane were used to transfer it into a glass conical tube; the $n$-hexane was evaporated under $\mathrm{N} 2$, and $0.5 \mathrm{~mL}$ chloroform/methanol(1:17.5,V: V) was added. The samples of PC and PE were kept at $-20^{\circ} \mathrm{C}$ until analyzed.

\section{HPLC-MS identification of the molecular species of PCs and PEs}

The Waters ZMD 4000 Platform HPLC-MS system was used to analyze the molecular species of PC and PE $[8,9]$. The species were separated by HPLC with a Symmetry RP-C18 column $(5 \mu \mathrm{m}, 250 \mathrm{~mm} \times$ $4.6 \mathrm{~mm}$ i.d)kept at $25^{\circ} \mathrm{C}$, at a flow rate of $1.0 \mathrm{~mL} \cdot \mathrm{min}^{-1}$ and an injection volume of $5.0 \mu \mathrm{L}$.For gradient elution, solutions $\mathrm{A}$ (chloroform/ methanol,1:17.5, $\mathrm{V}: \mathrm{V})$ and $\mathrm{B}($ acetonitrile/water, $1: 1, \mathrm{~V}: \mathrm{V})$ : from 0 to 5 min, A was kept constant at $80 \%$; from 5 to $8 \mathrm{~min}$, A was increased from 80 to $100 \%$; from 8 to $30 \mathrm{~min}$, A was kept constant at $100 \%$.
The instrument was operated in positive ion electrospray ionization mode [9]. The nebulizer gas and desolvation gas were nitrogen [10,11]. The velocity of the solution entering the MS was $10 \mu l \cdot \mathrm{min}^{-1}$. Typical operating parameters were as follows: capillary voltage $4.37 \mathrm{kV}$, cone voltage $47 \mathrm{~V}$, source temperature $100^{\circ} \mathrm{C}$, desolvation temperature $250^{\circ} \mathrm{C}$, gas flow $4.0 \mathrm{~L} \cdot \mathrm{h}^{-1}, \mathrm{~m} / \mathrm{z}$ range $200-1000$, and multiplier $700 \mathrm{~V}$. These conditions were optimized with a standard sample of C18:2 / C16:0 PC.

\section{GC-MS analyses of the fatty acid composition of PCs and PEs}

Samples of PCs and PEs were placed in $0.1 \mathrm{~mL}$ and dried under $\mathrm{N}_{2}$ The residues were analyzed by GC after the methyl ester reaction [12].

Phospholipid methyl esters: A $2.0-\mathrm{mL}$ volume of $14 \%$ BF3 in methanol(W:W) was added to samples of PC and PE to obtain methyl esters $\left(30 \mathrm{~min}\right.$ at $60^{\circ} \mathrm{C}, 2,2$-dimethoxypropane was used to scavenge the water of reaction), together with $1.0 \mathrm{~mL}$ of water and $1.0 \mathrm{~mL}$ of $\mathrm{n}$-hexane. This was shaken, and after cooling, the resulting mixture separated into two phases; the upper phase contained the fatty acid methyl esters,. The upper solution was decanted and evaporated under $\mathrm{N} 2$, and the residues were dissolved in $0.4 \mathrm{~mL}$-hexane.

GC-MS analysis of the methyl esters of PC and PE: The volatile compounds were identified and quantified using a GC/MS system(Trace GC/MS; Finnigan). The fatty acid methyl esters were separated on a PEG20M capillary chromatographic column $(30 \times 0.25 \times 0.25)$. The injection port of the $\mathrm{GC}$ was heated at $250^{\circ} \mathrm{C}$, and the transfer line to the mass spectrometer was maintained at $250^{\circ} \mathrm{C}$. The oven temperature was initially held at $180^{\circ} \mathrm{C}$ for $1 \mathrm{~min}$, and then heated at $3^{\circ} \mathrm{C} / \mathrm{min}$ to $230^{\circ} \mathrm{C}$ for $10 \mathrm{~min}$. The detection temperature was maintained at $230^{\circ} \mathrm{C}$. The carrying gas was $\mathrm{He}$ at a flow of $0.8 \mathrm{~L} \cdot \mathrm{h}^{-1}$. Mass spectra were obtained using a mass selective detector with electron impact at $70 \mathrm{eV}$, an ion source temperature of $200^{\circ} \mathrm{C}$, emission current of $150 \mu \mathrm{A}$, scan range of 33 to $450 \mathrm{~m} / \mathrm{z}$, and a detector voltage of $350 \mathrm{~V}$.

\section{Results and Discussion}

\section{Change in the intramuscular phospholipid component content}

Figure 1 shows the phospholipid content of duck meat cooked using different methods. All the phospholipids decreased during heating. The decrement in phospholipids was greater in roasted meat than in boiled meat, and the phospholipids were strongly oxidized and hydrolyzed under the more intense processing condition. Figure 1 show that the phospholipid content decreased in accord with the PE and PC levels. PC decreased more slowly than PE because it is more stable. The unstable PI and PS decreased quickly, while SPH and LPC decreased more slowly.

\section{Change in the PE and PC composition}

$\mathrm{PE}$ and $\mathrm{PC}$ were the main phospholipid components of duck meat. PE decreased faster than PC on cooking, as shown in Figure 2 and 3. The changes in PE and PC were closely related to their composition. The relative saturated fatty acid content increased markedly, while the relative polyunsaturated fatty acid content dramatically decreased, and the monounsaturated fatty acids decreased slightly. Arachidonic acid was reduced markedly, while linoleic acid decreased slightly.

\section{Change in the molecular species of PE and PC}

A marked difference was observed in the changes of the PE and PC molecular species. The relative C18:0/C20:4 content decreased more in 

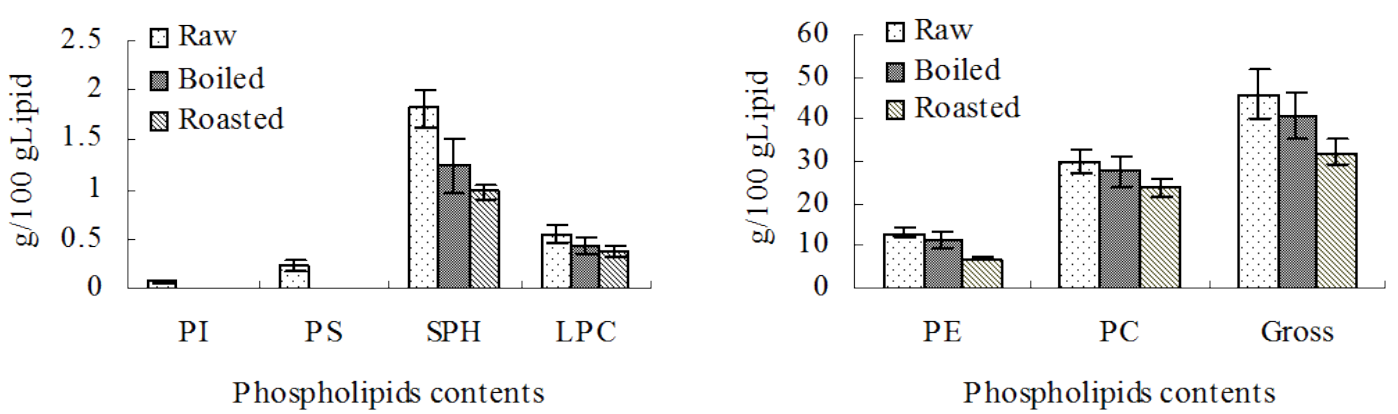

Figure 1: Influence of phospholipids contents by different heating methods

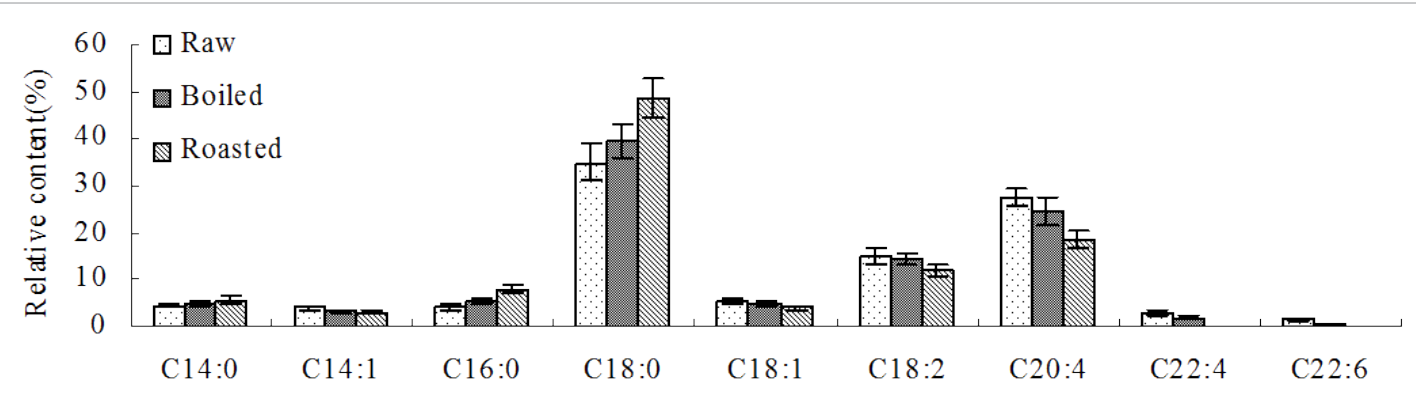

Fatty acids composition

Figure 2: Influence of fatty acids composition in PE by different heating methods.

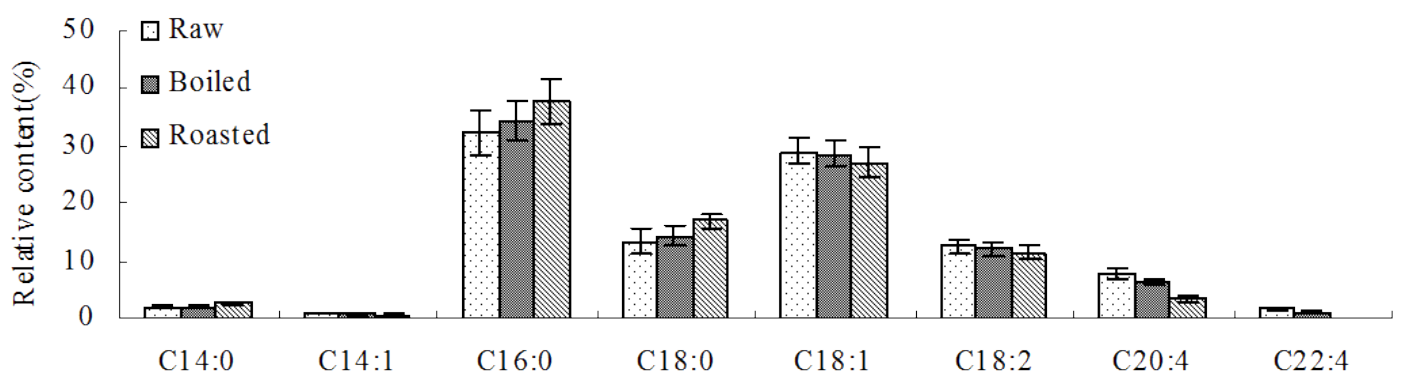

Fatty acids composition

Figure 3: Influence of fatty acids composition in PC by different heating methods.

PEs than in PCs, while the C18:1/C16:0 in PCs increased slightly, in accord with the fatty acid composition. The change in the PE molecular species was more marked than in PCs, reflecting the greater stability of PCs. Figure 4 and 5 showed that the relative polyunsaturated fatty acid content decreased, while the relative monounsaturated fatty acid content increased. Therefore, the change in polyunsaturated fatty acids was the reason for the changes in the phospholipids.

\section{Lipolysis of phospholipids}

The phospholipids in duck meat were strongly hydrolyzed on heating. Figure 6 showed that several phosphatidic acids were produced during the heating process. The phosphatidic acid content was low in the raw meat but increased in the boiled and roasted product. The roasted meat contained more phosphatidic acid than the boiled meat. To an extent, the amount of phosphatidic acid reflected the degree of phospholipid lipolysis, indicating that the phospholipids in duck meat are strongly hydrolyzed during the heating process.

\section{Discussion}

The main possible causes of the decrease in phospholipids in duck meat during cooking include the enzymatic degradation of phospholipids, heating degradation, the oxidation of phospholipids, the reaction between phospholipids and the decomposition products of fatty acid peroxide, the reaction between phospholipids and reducing sugars, and the brown stain reaction of phospholipids [13].

Since most enzymes are destroyed by heating, only a small amount of the decrease in phospholipids was due to enzymatic degradation. On heating, phospholipids break down to produce glycerol, inositol, phosphoric acid, phosphatidic acid, and so on. Phosphatidic acid was found in the heated samples on chromatographic analysis, indicating 


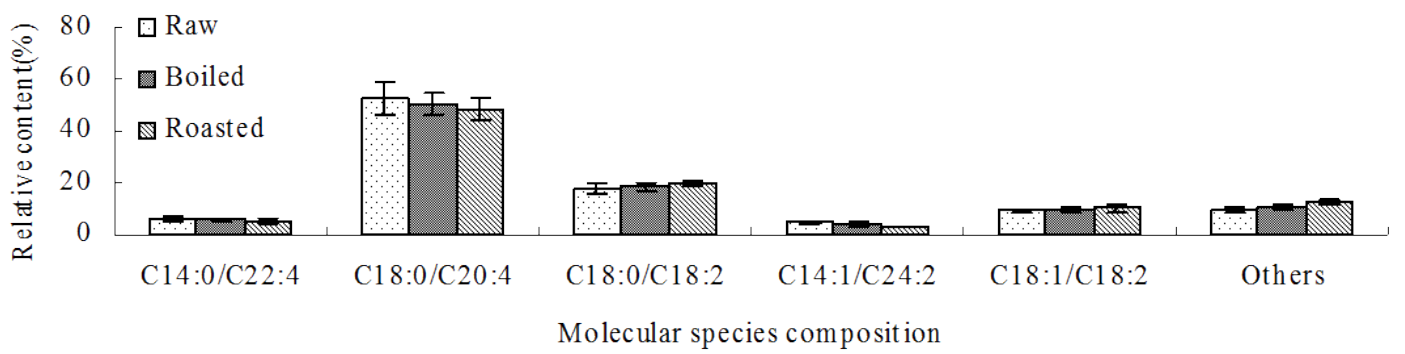

Figure 4: Influence of molecular species composition in PE by different heating methods.

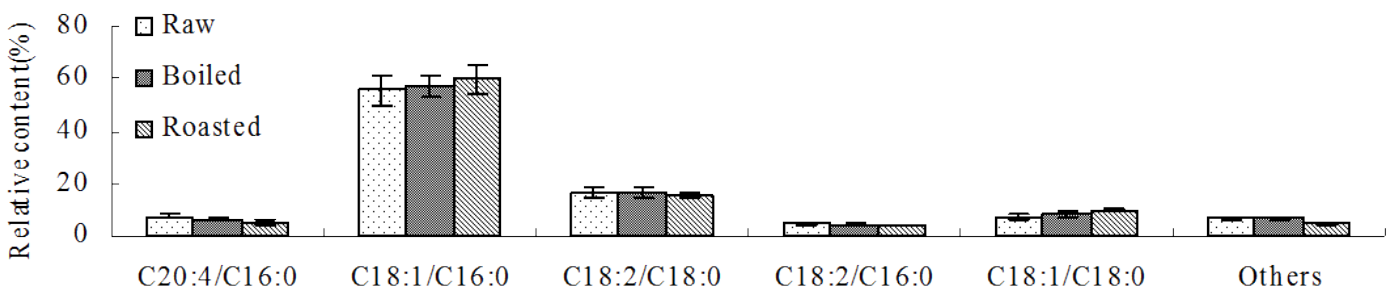

Molecular species composition

Figure 5: Influence of molecular species composition in PC by different heating methods.
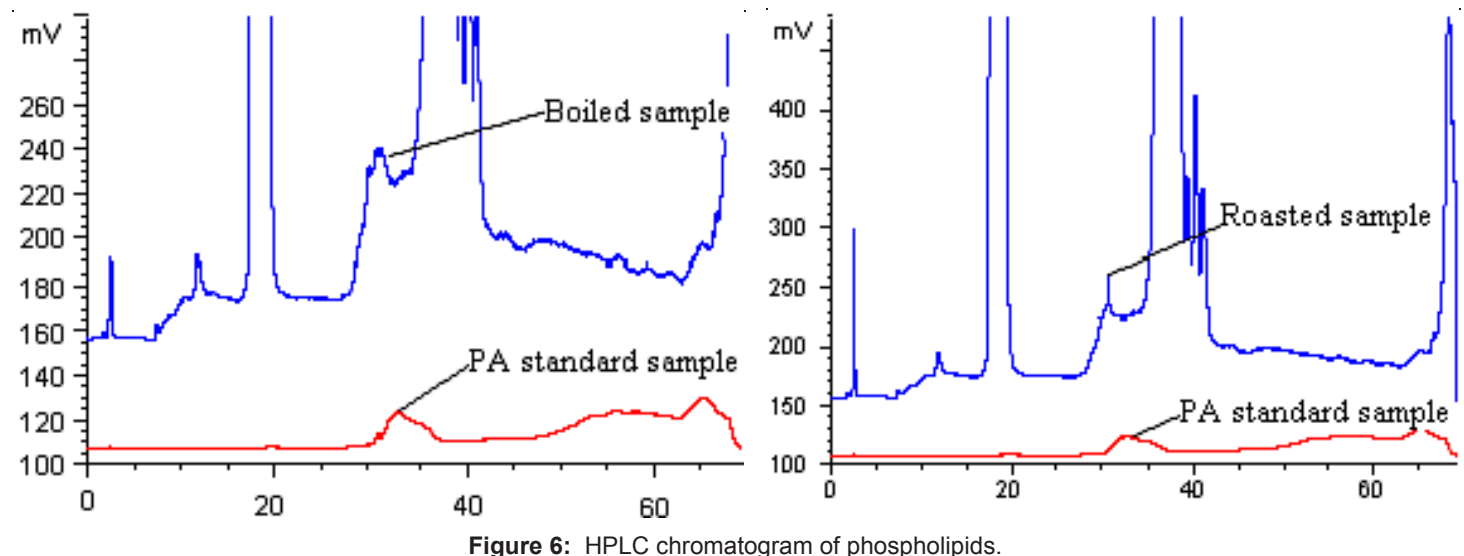

that some of the phospholipids were degraded. Since phospholipids contain several polyunsaturated fatty acids, it is believed that a large proportion of their reduction is caused by oxidation and the reaction with oxidation products [14]. The extreme complexity of a biological system makes it difficult to determine the main oxidation reaction involving intramuscular phospholipids [15]. In most studies on the organization of membranes, several conditions cannot be strictly controlled [1] The biosystem is inhomogeneous, and includes a hydrophilic water phase and a hydrophobic lipid phase [3]. Lipid oxidation always begins at the start site of membranous internal unsaturated fatty acids and most of the factors triggering lipid oxidation are located in the water phase [1]; thus, the triggering stage of lipid oxidation can only take place on the membrane, at the lipidosis position between muscle fibers(if active molecular diffusion occurs to the surface of aggraded fat), and on or in the double molecular layer. Iron is released from high-molecular-weight protein molecules at the point where iron bonds to the protein surface and to the lecithoid phosphoric site, which accelerates lipid oxidation [2]. The dissociated iron can chelate with organic acids and phosphoric acid, and the chelates might be the main catalysts of the lipid oxidation in muscle. Although the reaction between phospholipids and reducing sugars takes place mainly on heating, muscle has a low reducing sugar content, so this reaction has little effect on the loss of phospholipids. The brown stain reaction is an aldehyde /alcohol condensation reaction, catalyzed by basic substances. The phosphatidylcholine in phospholipids catalyzes the condensation reaction. The amidocyanogen in the brown stain reaction might be equivalent to the phosphatidylcholine of phospholipids and free sugars, and the bound sugar might provide the aldehyde needed in the brown stain reaction [2]. The aldehyde produced in the oxidation of phospholipid unsaturated fatty acid is a factor in the aldehyde/alcohol condensation reaction, so the brown stain reaction should result in the loss of a large proportion of the phospholipids. 
Citation: Wang DY, Liu F, Zhu YZ, Xu WM (2011) Changes of Phospholipids in Duck Muscle by Different Heating Methods. J Food Process Technol 2:121. doi:10.4172/2157-7110.1000121

Page 5 of 5

\section{Conclusions}

The phospholipid content of muscles decreased on heating duck meat, and roasting caused a greater lost of phospholipids than boiling. More PE was lost than PC. The loss of PE and PC was reflected in the relative decrease in the content of polyunsaturated fatty acids. The main reasons for the loss of phospholipids include heating degradation, phospholipid oxidation, and the brown stain reaction of phospholipids.

\section{Acknowledgements}

The authors are thankful to Mr. Dai Jun and Chen Shangwei at Southern Yangtze University for his technical assistance. This study was funded by National Natural Science Foundation of China(31071569) and Natural Science Foundation Program of Jiangsu Province(BK2009329, BK2010469).

\section{References}

1. Malavolta M, Bocci F, Boselli E, Frega NG (2004) Normal phase liquid chromatography-electrospray ionization tandem mass spectrometry analysis of phospholipid molecular species in blood mononuclear cells: application to cystic fibrosis. J Chromatogr B Analyt Technol Biomed Life Sci 810: 173-186.

2. Przybylskl R, Eskin NAM (1991) Phospholipid Composition of Canola Oils During the Early Stages of Processing as Measured by TLC with Flame Ionization Detector. Journal of the American Oil Chemists' Society 68: 241-245.

3. Timon ML, Ventanas J, Carrapiso Al (2001) Subcetaneous and intrermuscular fat characterization of dry-cured Iberian hams. Meat Science 58: 85-91.

4. Gandemer G, Kim I E (1993) Quelques éléments objectifs de comparaison de la qualité de la viande de poulets label et standard. Proc. Poultry meat 11:119127.

5. Folch J, Lees M, Stanley GHS (1957) A silmple method for isolation and purification of total lipids from animal tissues. J Biol Chem 226: 497-509.
6. García RJA, Gibert J, Díaz I (1994) Determination of neutral lipids from subcutaneous fat of cured ham by capillary gas chromatography and liquid chromatography. J Chromatogr A 667: 225-233.

7. Lesnefsky JE, Stoll MS, Minkler PE, Hoppel CL (2002) Separation and quantitation of phospholipids and lysophospholipids by high-performance liquid chromatography. Anal Biochem 285: 246-254.

8. Gary D, Nigel D (2001) Analysis of phospholipid molecular species by liquid chromatography atmospheric pressure chemical ionisation mass spectrometry of diacylglycerol nicotinates. Chem Phys Lipids 111: 1-17.

9. Barroso B, Bischoff R (2005) LC-MS analysis of phospholipids and lysophospholipids in human bronchoalveolar lavage fluid. Journal of Chromatography B 814: 21-28.

10. Dobson G, Deighton N (2001) Analysis of phospholipid molecular species by liquid chromatography-atmospheric pressure chemical ionisation mass spectrometry of diacylglycerol nicotinates. Chem Phys Lipids 111: 1-17.

11. Deborah P, Emanuele B, Howard W (2005) High performance liquid chromatography-tandem mass spectrometry of phospholipid molecular species in eggs from hens fed diets enriched in seal blubber oil. J Chromatogr A 1097: 66-73.

12. Isaac G, Bylund D, Månsson JE, Markides KE, Bergquist J (2003) Analysis of phosphatidylcholine and sphingomyelin molecular species from brain extracts using capillary liquid chromatography electrospray ionization mass spectrometry. J Neurosci Methods 128: 111-119.

13. Sugino H, Ishikawa M, Nitoda T (1997) Antioxidative Activity of Egg Yolk Phospholipids. Journal of Agricultural and Food Chemistry 45: 551-554.

14. Yang HJ, Ma CW, Qiao FD (2005) Lipolysis in intramuscular lipids during processing of traditional Xuanwei ham. Meat Science 71: 670-675.

15. El-Sebaiy LA, Metwalli SM, Khalil ME (1987) Phospholipid changes in muscles of plathead grey mullet(Mugil cephalus) during frozen storage. Food Chemistry 26: 85-96. 